\title{
Accidental Perforation of Subarachnoid Space with Spinal Introducer
}

\author{
Luiz Eduardo Imbelloni ${ }^{1 *}$ and Micaela Barbosa L Sales ${ }^{2}$ \\ ${ }^{1}$ Anesthesiologist, Hospital de Trauma, João Pessoa, Brazil \\ ${ }^{2}$ Anesthesiology, Resident, Hospital de Trauma, João Pessoa, Brazil
}

*Corresponding author: Luiz Eduardo Imbelloni, MD, Anesthesiologist, Hospital de Trauma, João Pessoa, Rua Marieta Steimbach Silva, 106/1001, Miramar, 58043-320, Brazil

\begin{abstract}
Background: The existence of fine gauge needles with a traumatic bevel, pencil tip type; it is possible to increase the indication of spinal anesthesia in young people and to reduce the incidence of post-puncture headache. We present a case of a post-dural puncture headache occurring after perforation dura mater using a 20-gauge needle introducer for spinal anesthesia with Whitacre needle.

Case report: A 34-year-old man (body weight $67 \mathrm{~kg}$, height $176 \mathrm{~cm}$, ASA I) with right femoral diaphysis fracture. After analgesia with inguinal lumbar plexus block, spinal anesthesia using a $20 \mathrm{G}$ needle introducer before inserting the $27 \mathrm{G}$ Whitacre needle. At first attempt, removal of the Whitacre stylet demonstrated CSF completely filling the needle hub. The introducer needle was withdrawn immediately. New punction was performed at L4-L5 level and single lumbar puncture via median with $27 \mathrm{G}$ Whitacre needle through the $20 \mathrm{G}$ introducer guide. After dripping of CSF, $15 \mathrm{mg}$ of $0.5 \%$ isobaric bupivacaine was administered. After 48 hours the patient reported PHDP. Within three days the postural headache settled with conservative treatment consisting of oral analgesia while maintaining adequate hydration.
\end{abstract}

Conclusions: The introducer needle does carry the risk of accidental dural puncture, and this fact happened in our patient using the $20 \mathrm{G}$ introducer of $35 \mathrm{~mm}$ in length resulting in severe headache and lasting for three days.

\section{Keywords}

Spinal anesthesia, Introducer needle, Complications, Headache

\section{Introduction}

An introducer needle is often used as a means of stabilizing subsequent placement of a small-gauge needle during spinal anesthesia. The introducer was a purpose-designed reusable needle designed by Sise [1] in the 1920s for use with the spinal needles available at the time and was in regular use until the early 1990s when disposable introducers were introduced. The Sise needle resembled a large drawing pin in general shape but had a cannulated needle shaft of $5 \mathrm{~cm}$ with a cutting tip. In 1942, a new guide-introducer was designed for use in spinal and epidural anesthesia [2]. The needle slides through its guide without side-play. This aids the introduction of a fine Pitkin needle, preventing it from bending and keeping it on a straight.

In many patients the distance to the cerebrospinal fluid (CSF) does not require use of the total length of the spinal needle. The length of the spinal needles depends on the manufacturer. The needles manufactured by B. Braun are $88 \mathrm{~mm}$ long, Becton-Dickinson $89 \mathrm{~mm}$ long and Unisis $90 \mathrm{~mm}$ long. The introducers can be of different sizes (18G, 20G and 22G) and also their length depends on the manufacturer.

The objective of this case report was to demonstrate the accidental perforation of the dura mater with the use of the 20G introducer for spinal anesthesia with pencil point needle.

\section{Case Report}

Man patient, 34-years-old, $67 \mathrm{~kg}, 176 \mathrm{~cm}$ high, physical status ASA I, with no history of drug allergy, electively admitted for surgical of right femoral diaphysis fracture. Preoperative routine laboratory analyses revealed normal complete blood count and biochemical parameters. We obtained informed consent and discussed the anesthetic technique with the family.

The morning of surgery and 120 minutes before anesthesia, the patient received orally $200 \mathrm{~mL}$ of carbo-

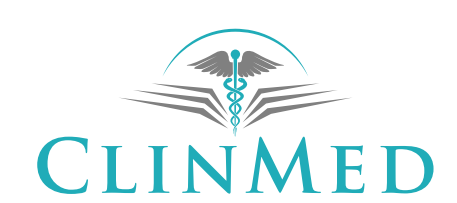

INTERNATIONAL LIBRARY

Citation: Imbelloni LE, Sales MBL (2018) Accidental Perforation of Subarachnoid Space with Spinal Introducer. Int J Anesthetic Anesthesiol 5:074. doi.org/10.23937/2377-4630/1410074

Accepted: October 15, 2018: Published: October 17, 2018

Copyright: (C) 2018 Imbelloni LE, et al. This is an open-access article distributed under the terms of the Creative Commons Attribution License, which permits unrestricted use, distribution, and reproduction in any medium, provided the original author and source are credited. 
hydrate-enriched solution (Fresenius Jucy ${ }^{\circledR}$ ) in order to abbreviate preoperative fasting. The patient was placed on the operating room table and after venoclysis with an $18 \mathrm{G}$ catheter and Ringer with lactate infusion her heart rate $(\mathrm{HR})$, systolic blood pressure (SBP), diastolic blood pressure (DBP), and peripheral oxygen saturation $\left(\mathrm{SpO}_{2}\right)$ were monitored, and preoperative measures were recorded. In addition, he was administered oxygen $\left(\mathrm{O}_{2}\right)$ at a rate of $2 \mathrm{~L} / \mathrm{min}$ through a nasal catheter. The patient was sedated with $1 \mathrm{mg}$ of midazolam and $50 \mu \mathrm{g}$ of fentanyl, intravenously. Immediately after monitoring and sedation, we performed an inguinal lumbar plexus block. A single $50 \mathrm{~mm}$ insulated needle Stimuplex ${ }^{\circledR}$ A (B. Braun Melsungen AG, Germany) connected to an HNS 12 Stimuplex ${ }^{\circledR}$ (B. Braun Melsungen AG, Germany) stimulator $(0.30 \mathrm{~ms}$ stimulus at $2 \mathrm{~Hz}$ frequency with an initial current intensity of $0.5 \mathrm{~mA}$ ) was inserted at point of the needle. The needle was advanced lateral to femoral artery and quadriceps and patella contraction was obtained; then, $20 \mathrm{~mL}$ of the anesthetic solution $0.25 \%$ levobupivacaine (Cristália Prod. Quím. Farm. Ltda) plus $20 \mathrm{~mL}$ of $2 \%$ lidocaine with epinephrine (Cristália Prod. Quím. Farm. Ltda) was injected.

In the post-anesthetic evaluation performed by telephone within approximately 48 hours of the procedure, the patient had a predominantly frontal, non-pulsatile headache, with a high intensity (8/10 on Visual Analog Scale of pain), associated with nausea and low back pain, worsening in the supine position and improvement in position of dorsal position. Within three days the postural headache settled with conservative treatment consisting of oral analgesia while maintaining adequate hydration. An epidural blood patch was felt unnecessary due to the gradual clinical improvement. There was no neurological sequela.

\section{Discussion}

The use of extremely fine cannulae for dural puncture has been reported to present technical problems [3-5]. Pencil tip needles use the introducer to reach the subarachnoid space.

Spinal anesthesia can be performed with a sharpedged needle or pencil-tip needle. The subarachnoid space can be reached in two ways. The first consists of passing a small spinal needle through the skin, several fibrous ligaments, and then into the subarachnoid space. The other approach uses a large bore introducer needle to penetrate the skin and fibrous layers. The fine gauge spinal needle (Quincke or Whitacre) can then pass through the larger introducer needle with less resistance, guided by the stiffer needle's shaft, toward the dura mater. The use of a larger bore introducer needle may cause significant tissue trauma and accidental perforation $[3,4]$.

In 1985, the depth of the epidural space at different intervertebral interspaces was measured in 1,000 parturients [6]. Overall the median distance from the skin to the epidural space was $4.7 \mathrm{~cm}$, but this varied with the lumbar interspace at which it was measured, being greatest at the third (L3-L4) interspace $(4.93 \mathrm{~cm})$ and least at the first (L1-L2) interspace $(4.23 \mathrm{~cm})$. In 1991, the skin-to-extradural-space distance was recorded for 3,011 women in labour, and the depth of extradural space was considered shallow $(2-4 \mathrm{~cm})$, normal $(4-6 \mathrm{~cm})$ and deep $(6-9 \mathrm{~cm})$ [7]. The depth score in obstetric patients was shallow at $16 \%$, normal at $76 \%$ and deep at $8 \%$. However, this measure was not found in non-obstetric patients. Care must be taken when introducing an introducer needle and it is suggested that the initial insertion should be to a depth of no more than $2 \mathrm{~cm}$

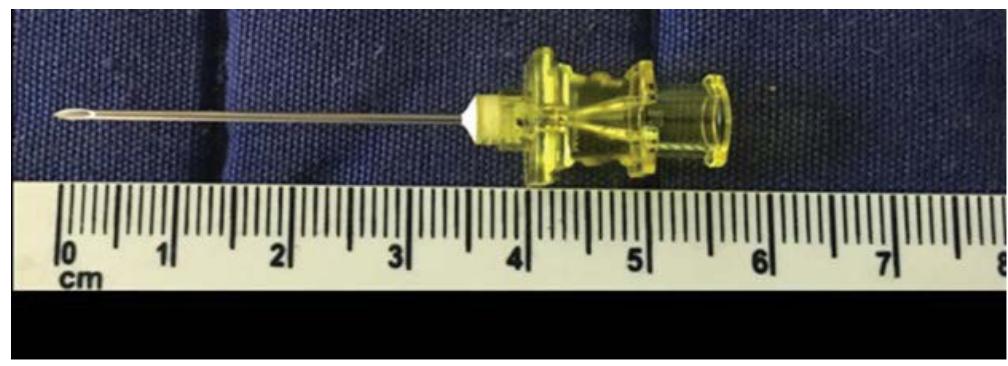

Figure 1: 20G Introducer (B.Braun, Germany).

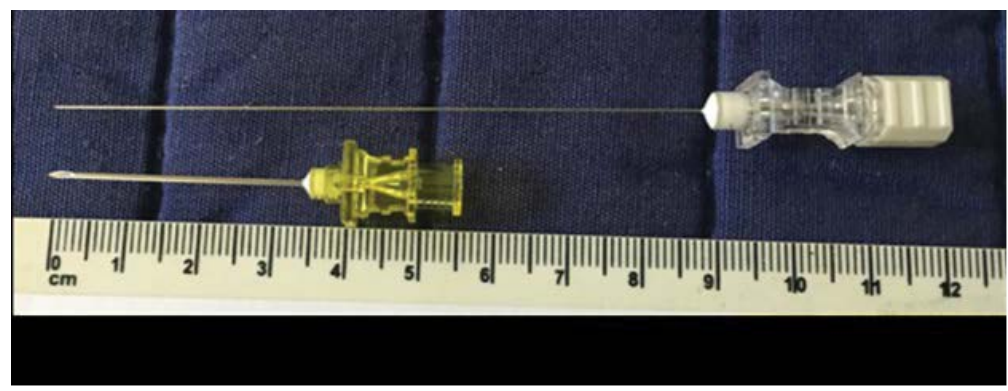

Figure 2: Introducer and 27G Whitacre needle (both B.Braun, Germany). 


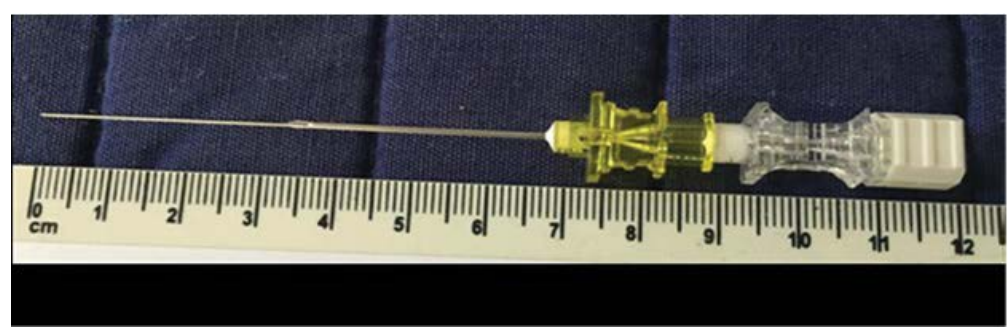

Figure 3: $27 \mathrm{G}$ Whitacre needle inside the introducer.

[7]. If the introducer was fully placed only $3.3 \mathrm{~cm}$ from the spinal needle will be used to reach the subarachnoid space (Figure 1, Figure 2, and Figure 3). Thus some authors recommend that the introducer not be introduced more than $2 \mathrm{~cm}$ to avoid accidental puncture of the dura mater, which corresponds a sufficient distance to facilitate penetration of the needle [5].

In order to reduce the incidence of PDPH, the use of thinner spinal needles is a worldwide practice. However, the flip-side to this practice is that an introducer is required since the thinner spinal needles do not have the rigidity and strength to traverse the tough skin and superficial ligaments, especially in elderly individuals who tend to have superficial calcified ligaments. The compatibility between spinal needles and their introducers varies between manufacturers and can significantly influence the usable length of the spinal needle available resulting in failure to locate CSF in larger patients.

The introducer needle does carry the risk of accidental dural puncture [4], and this fact happened in our patient using the $20 \mathrm{G}$ introducer of $35 \mathrm{~mm}$ in length resulting in severe headache and lasting for three days.

\section{References}

1. Sise LF (1928) A device for facilitating the use of fine gage lumbar puncture needles. JAMA 91: 1186.

2. Rowbothan S (1942) Introducer for spinal needles. Lancet 239: 734.

3. Flaatten H, Rodt SA, Vamnes J, Rosland J, Wisborg T, et al. (1989) Postdural puncture headache. A comparison between $26-$ and 29 -gauge needles in young patients. Anaesthesia 44: 147-149.

4. Dahl JB, Schultz P, Anker-Moller E, Christensen EF, Staunstrup HG, et al. (1990) Spinal anaesthesia in young patients using a 29-gauge needle: Technical considerations and an evaluation of postoperative complaints compared with general anaesthesia. Br J Anaesth 64: 178-182.

5. Benito MC, Alvarez MB, Sánches ML, Mora J (1995) Punción accidental del saco dural con un introductor de aguja espinal (Cartas al Director). Rev Esp Anestesiol Reanim 42: 107.

6. Harrison GR, Clowes NWB (1985) The depth of the lumbar epidural space from the skin. Anaesthesia 40: 685-687.

7. Sutton DN, Linter SPK (1991) Depth of extradural space and dural puncture. Anaesthesia 46: 97-98. 